\title{
COMMUNICATIONS
}

\section{PRESSURE CHANGES IN THE OPHTHALMIC ARTERY AFTER CAROTID OCCLUSION AN EXPERIMENTAL STUDY IN THE RABBIT*}

BY

\author{
VERNON H. SMITH \\ Manchester Royal Eye Hospital
}

IN recent years ophthalmologists have become increasingly aware of the syndrome of carotid occlusion, as many patients with this condition present themselves complaining of ocular symptoms. Indeed, these may be the only symptoms, and the responsibility of the ophthalmologist is considerable when he alone has the chance of detecting the condition. The two commonest ocular symptoms associated with this syndrome are homolateral blindness and crossed hemianopic field defects. The latter have been ascribed with some certainty to lesions of the middle cerebral artery (Walsh and Smith, 1952), and are unlikely to be present without associated systemic symptoms; but homolateral blindness, whether transient or permanent, may be the patient's only complaint.

This second group of cases, originally the sole responsibility of the ophthalmologist, has been the subject of considerable study. Reasonable though not wholly satisfactory explanations have been advanced for the development of optic atrophy, but the mechanism of the transient attacks of blindness is still unknown and further investigation is required.

Although it is known that grave alterations in the blood pressure occur distal to stenosis or occlusion of a carotid artery (Sweet and Bennett, 1948; Sweet, Sarnoff, and Bakay, 1950; Bakay and Sweet, 1952, 1953), the fact that not all patients with carotid occlusion suffer from transient attacks of blindness or permanent optic atrophy (Johnson and Walker, 1951) suggests that further knowledge of the blood pressure between the central retinal artery and the carotid block would be desirable.

Duke-Elder (1926) has shown that, in the normal anaesthetized cat, there is a 25 per cent. fall in pressure from the ophthalmic artery to the central retinal artery; correspondingly any fall in pressure in the ophthalmic artery is likely to give rise to an even lower pressure in the retinal vessels.

The studies of Sweet and his collaborators on pressure changes in the carotid artery and its branches distal to an occlusion have not been performed in the case of the ophthalmic artery. These workers were well aware of the value of such a reading, but the inaccessibility of the vessel made the introduction of a cannula technically impossible.

* Received for publication July 7, 1960 . 
The technique of ophthalmodynamometry has also been used to measure the pressure in the ophthalmic artery in carotid occlusion, but although useful clinically the results are not sufficiently accurate to provide evidence for basic pathological assumptions.

Failing a method of clinical investigation, resort has been made to the experimental animal, The method used by Duke-Elder (1926) to measure the ophthalmic arterial pressure in the cat suggested itself. There are, however, certain technical difficulties, as Duke-Elder himself pointed out, and in the slightly different problem studied in this investigation substantial modifications to the original method have been needed.

\section{Technique}

In Duke-Elder's original investigations the pressure in the ophthalmic artery was measured by inserting into the eye a needle from a pressure apparatus, to which was connected a manometer. The intra-ocular pressure was then gradually raised. This caused a build-up in the pressure in the central artery of the retina until it was equal to that in the ophthalmic artery. When pulsations of blood were still just visible at the disc when looking through an ophthalmoscope, the intra-ocular pressure was just less than that in the ophthalmic artery.

Even under ideal experimental conditions this end-point was not easy to detect; if the needle was placed in the anterior chamber it often interfered with ophthalmoscopy, and if it was placed in the posterior segment it often caused a vitreous haemorrhage.

These difficulties have been confirmed by the present author, who also found an additional complication when the carotid artery was ligated, in that there was a vast reduction in the pulse pressure in the ophthalmic artery. This made the end-point even harder to detect, as Duke-Elder's method depended on a vigorous pulse pressure for the easy identification of this critical level.

To overcome this difficulty the author introduced a vital dye (Pontamine sky blue) into the circulation of the experimental animal. The intra-ocular pressure was raised to well above the blood pressure before the dye was injected, and was then lowered gradually.

An end-point similar to that observed by Duke-Elder was seen in animals in which the carotid had not been ligated, although the dye was not so great a help as had been expected; however, in cases in which the ipsilateral common carotid artery had been ligated the results were still difficult to assess. The small or absent pulse pressure allowed an insidious seepage of blood to enter the retinal vessels as the intra-ocular pressure was reduced, and the vascularized part of the fundus gradually assumed a bluish tinge.

This problem was only solved by sacrificing the eye and the animal. The intra-ocular pressure was kept at a desired level for some minutes and the optic nerve was then clamped, isolating and stabilizing the retinal circulation, and the eye was removed. A subsequent flat preparation of the retina showed without doubt whether there was blue dye in the eye or not. 
This method was used in all the experiments from which deductions are made, and may be summarized as follows:

If the intra-ocular pressure is raised until it is above the ophthalmic arterial pressure, and a vital dye is then injected; depending on the subsequent intraocular pressure, on removal of the eye a flat preparation of the retina will contain dye only if the intra-ocular pressure has fallen below that in the ophthalmic artery.

(1) Choice of Experimental Animal.-This lay between the monkey and the rabbit. Amongst common experimental animals they alone possess neither a carotid rete nor a well-marked ramus anastomoticus (Henderson, 1903; Duke-Elder, 1958). Such massive anastomoses between the carotid arteries are of course not present in man, and experiments on animals possessing them can have little relation to human physiology in this respect.

For the method described in this paper the rabbit has one advantage (apart from expense) over the monkey, in that the rabbit's orbit is shallow, allowing easy access to the optic nerve for clamping.

The central retinal artery of the rabbit arises as the main branch of the superior ophthalmic artery. This vessel is a branch of the internal carotid while it is actually forming part of the circle of Willis, and before entering the optic nerve it gives a branch to the long ciliary artery-a branch of the external carotid.

After the central retinal artery enters the optic nerve it runs forwards until it reaches the disc, where it divides into two branches, which immediately subdivide to form a vascularized area in the retina resembling, with the disc, the two blades of an aeroplane propeller. This is the only area of the retina that contains blood vessels (Duke-Elder, 1958; Michaelson, 1954).

The rest of the blood supply of the eye comes from the external carotid artery. However, the retinal circulation of the rabbit is probably separate from that of the choroid as in man; Sautter and Seitz (1952) showed that there was no functional connexion between the two, and their experiments have been repeated and confirmed. The subendothelial cushions in the ciliary vessels which had been thought to regulate flow from the choroidal to the retinal circulation (Moffat, 1952, 1956) are now only doubtfully cast in this role, and may indeed be artefacts (Moffat, 1959).

The circle of Willis in the rabbit is also very similar to that in man (MacDonald and Potter, 1951), and a block in the internal or common carotid might be expected to have pressure effects similar to those seen in man, the main difference being that in the rabbit the anastomotic value of the circle is slightly higher, as the posterior communicating artery seems to be a more constant and relatively larger branch.

(2) Anaesthesia.-This was always induced by intravenous Nembutal and maintained by open ether. The Nembutal was injected into the marginal vein of the ear, and the amount required varied considerably from animal to animal, not being accurately proportionate to weight. 
(3) Control of the Intra-ocular Pressure.-The apparatus (Fig. 1) consisted of a Winchester jar to which was attached a "Y" tube. To one limb of this was attached a Higginson syringe, and to the other limb another " $Y$ " tube.

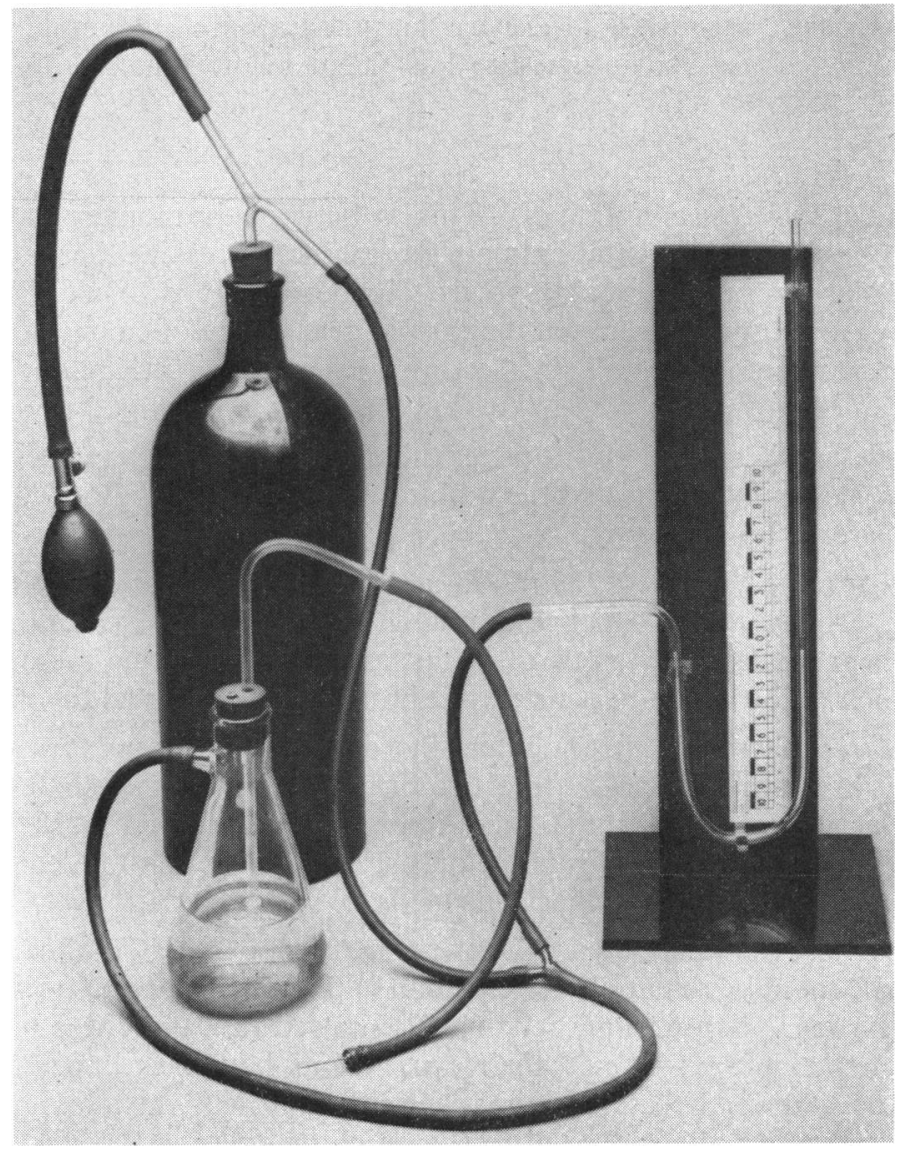

Fig. 1.-Apparatus for the control of the intra-ocular pressure. For details see text.

To this was attached a compensated mercury manometer graduated in millimetres, and the remaining limb was fed into a flask containing saline.

Air under controlled pressure could thus be forced into the flask onto the surface of the saline, which in turn was forced out along the tubing through a No. 1 (Record) needle into the eye.

By using a Winchester jar a large reservoir of air was provided, the pressure of which could be altered as gradually and evenly as desired by the Higginson syringe.

The needle was inserted at the limbus into the anterior chamber. Introduction into the posterior segment ran too great a risk of damaging the retina.

(4) Estimation of Blood Pressure.-In most cases this was recorded by cannulating the common carotid artery downwards towards the aorta, but occasionally this was impossible for technical reasons, and then the femoral artery was used instead. 
This gave exactly the same readings as the carotid, as has been verified (Experiment 38).

Polythene tubing (Allen and Hanbury, No. 2, internal diameter $1.0 \mathrm{~mm}$.) was used for cannulation in all experiments. This was connected to a compensated mercury manometer calibrated in millimetres (Fig. 2); interposed was a syringe connected to a two-way tap, by which the cannula could be cleared of blood.

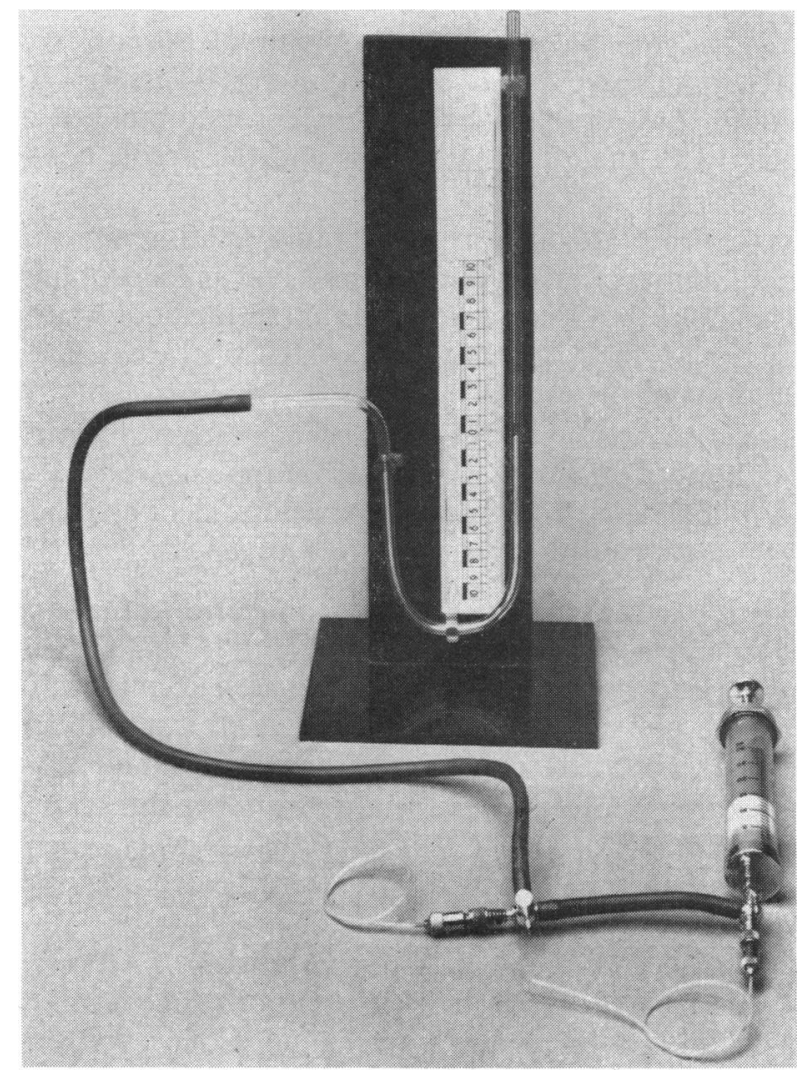

FIG. 2.-Apparatus for the measurement of blood pressure. For details see text.

In the second series of experiments an additional cannula was introduced into the common carotid distal to the ligature. This was also connected to the manometer, so that the same instrument was used to give pressure readings from above and below the carotid ligature.

(5) Choice of Vital Dye.-The dye used in practically all the experiments was Pontamine sky blue (supplied by Messrs. Gurr and Co.). This dye was used on the recommendation of Professor A. C. P. Campbell, who had used it on a previous occasion with success (Campbell, 1937), because of its slow penetration across the blood-brain barrier. This last property suggested a slow rate of diffusion across the retinal vessel wall. 
An average of $20 \mathrm{ml}$. of a 10 per cent. solution was injected, usually intravenously though sometimes intra-arterially. After the injection the blood pressure usually fell, often to as low as 50 per cent. of its original value, but it recovered rapidly to a level a little below that before the injection. Thereafter the blood pressure gradually declined.

In all cases the non-operated eye was removed as a control, to show that the dye had penetrated to the retinal vessels. This it did in every case.

(6) Fixation of the Retinal Circulation.-A pair of Spencer-Wells forceps was applied across the optic nerve to trap the central retinal vessels. The eye was then removed, cutting the nerve proximal to the forceps, and plunged into 10 per cent. formalin complete with the attached forceps and the needle connecting it to the pressure apparatus.

In earlier experiments attempts at more rapid fixation were made, using the method of rapid freezing. Carbon dioxide snow and an Isopentane bath suspended in liquid nitrogen were both employed, but these methods were unsatisfactory. Instant freezing turned the vitreous to ice, which on expanding completely disorganized the interior of the eye.

Several other fixatives were used before 10 per cent. formalin emerged as the most suitable. The addition of 4 per cent. ammonium molybdate to the formalin unfortunately left the retina too brittle. Absolute alcohol produced too much shrinkage, and Susa gave results intermediate between the two.

(7) Preparation of the Slide.-The eye, still connected to the pressure apparatus and with the optic nerve still clamped, was placed in formalin. In some cases the needle from the pressure apparatus was removed after 20 minutes, and in others it remained in situ, the pressure gradually decreasing over a number of days. The results did not seem to be affected whichever technique was adopted.

Quite often the artery forceps were removed after a thread ligature had been passed between them and the globe. In experiments where this was done, care was taken to tie the ligature before the needle from the pressure apparatus was removed from the eye.

The eye was fixed in 10 per cent. formalin for a week. After fixation the globe was sectioned $5 \mathrm{~mm}$. from the limbus and the anterior segment was discarded. The retina was detached from the posterior segment and, as it needed no further staining, was placed on a slide, dehydrated, and mounted.

\section{(I) Control Series}

\section{Experimental Procedure and Results}

\section{(a) Procedure}

(1) The rabbit was anaesthetized as described.

(2) The left common carotid artery was exposed and ligated. A polythene cannula was inserted proximal to the ligature pointing downwards to the aorta, which was kept clear by the assistant. Readings were taken from the manometer.

(3) The right eye was prepared. Medial and lateral canthotomy were performed, and the conjunctiva was incised round the limbus and separated from the globe. The superior and lateral recti were then detached from their insertions. 
Using the medial rectus for fixation, the needle from the pressure apparatus was introduced into the anterior chamber at the limbus, and the intra-ocular pressure was raised to approximately $30 \mathrm{~mm}$. $\mathrm{Hg}$ above the blood pressure.

(4) Using the marginal vein of the ear, $20 \mathrm{ml}$. of a 10 per cent. solution of Pontamine sky blue were injected. The animal was seen to turn blue.

(5) When the blood pressure was steady, as described above, the intra-ocular pressure was reduced to the desired level for a measured period. It was then raised again to $30 \mathrm{~mm}$. $\mathrm{Hg}$ above the blood pressure.

(6) The remaining recti were now detached. The optic nerve was clamped with artery forceps and then divided proximal to them. The globe was then plunged into formalin as described.

(7) The remaining eye was now excised in a similar fashion, the optic nerve being clamped and divided proximally. This was also fixed in formalin, and flat preparations of the two eyes were subsequently made as already described.

(8) All animals were killed at the end of the experiment, usually with an overdose of anaesthetic.

(b) Results.-As can be seen (Fig. 3), when the intra-ocular pressure is maintained at the same level as the blood pressure, no blue dye enters the eye, indicating that this pressure is above that in the ophthalmic artery.

When, however, the intraocular pressure is lowered as little as $5 \mathrm{~mm}$. $\mathrm{Hg}$ below that of the blood pressure, dye enters the eye in every case. This implies that the pressure in the ophthalmic artery is within $5 \mathrm{~mm}$. $\mathrm{Hg}$ of the blood pressure as measured by the method described.

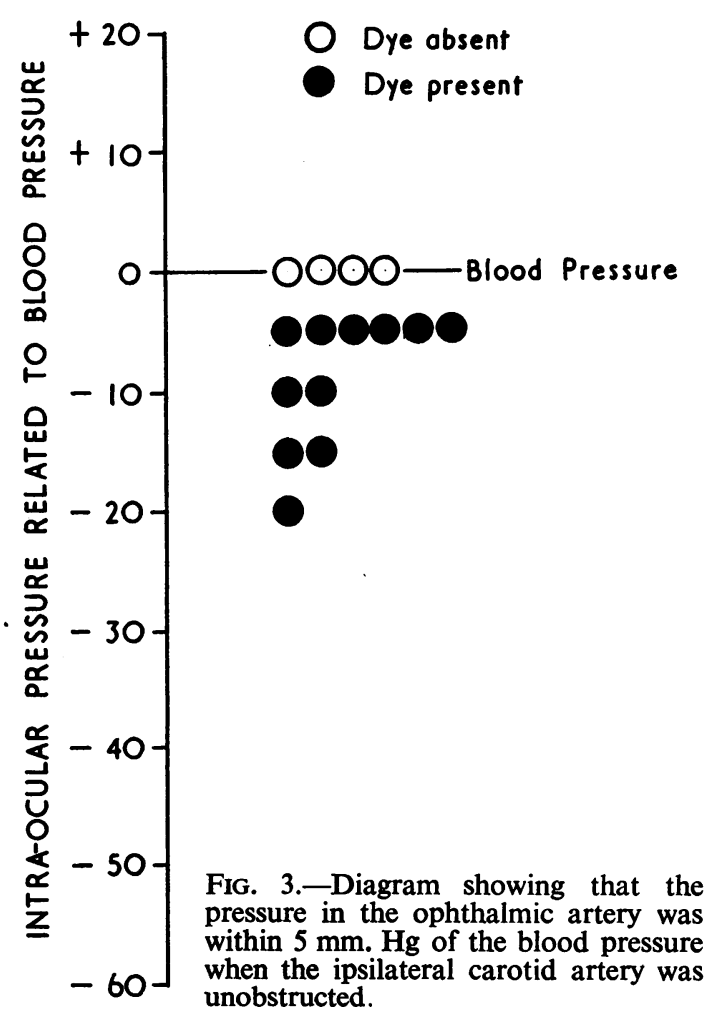

\section{(II) SERIES I}

(a) Procedure.-This was the same as that in the control series, with the difference that the carotid ligated was the left and the eye that was prepared and experimented on was also the left. 
In this series also the intraocular pressure was varied in relation to the blood pressure, but at a lower level.

(b) Results. - As can be seen (Fig. 4), when the intra-ocular pressure was reduced to as low as $40 \mathrm{~mm}$. $\mathrm{Hg}$ less than the blood pressure, in no case did any blue dye enter the eye, implying that in every case the blood pressure in the ophthalmic artery was less than this.

As the intra-ocular pressure was reduced, however, in a number of cases the pressure in the ophthalmic artery was sufficient to force blood into the eye. The pressure of 50 mm. Hg less than the blood pressure seemed to be a kind of watershed, positive and negative results occurring in fairly equal quantities.

At $55 \mathrm{~mm}$. $\mathrm{Hg}$ below the blood pressure, the intraocular pressure was definitely below that in the ophthalmic artery, as was shown by the presence of dye in the eye in every case.

\section{(III) SERIES II}

\section{(a) Procedure}

(1) The rabbit was anaesthetized.

(2) The left common carotid artery was ligated. A polythene cannula was introduced proximal to the ligature pointing downwards towards the aorta. While this was kept clear by the assistant, a second cannula was inserted distal to the ligature pointing upwards towards the head. Sometimes it was possible to introduce this into the internal carotid artery, but most often it remained in the common carotid artery.

(3) The left eye was prepared as in the control series, the intra-ocular pressure being raised to about $30 \mathrm{~mm}$. $\mathrm{Hg}$ above the blood pressure.

(4) $20 \mathrm{ml}$. of 10 per cent. Pontamine sky blue were injected intravenously. 
(5) For a controlled period the intra-ocular pressure was reduced to a determined level in relation to the pressure recorded from the cannula placed distal to the carotid ligature. After this it was again raised to about $30 \mathrm{~mm}$. $\mathrm{Hg}$. above the blood pressure.

(6) The left eye was removed as in the earlier series, followed by the right.

(7) The animal was killed.

(b) Comment.-The second cannula, introduced distal to the carotid ligature, provides a reading of the pressure in the circle of Willis at the point where the internal carotid artery takes place in it. As has been stated above, it was not possible to insert the cannula into the internal carotid in every case, but it is unlikely that there is any difference in pressure between the common and internal carotid arteries sufficiently large to be recorded by the relatively crude methods used. There seemed to be no difference in the results obtained when the cannula was placed in one or the other vessel.

This technique then affords some measure of the fall in pressure in the carotid artery after ligation.

It also carries with it a further technical complication. When washing out the cannula with saline it is possible to raise the pressure in the circle of Willis by undue pressure on the syringe, and so to force blood into the eye after overcoming the raised intra-ocular pressure. Because of this unexpected results may be obtained, and indeed Experiments 84 to 86 were invalidated for this reason.

(c) Results.-As can be seen (Fig. 5), in no case did dye reach the retina in which the intra-ocular pressure was raised to as little as $5 \mathrm{~mm}$. Hg above the pressure recorded from the cannula placed distal to the carotid ligature.

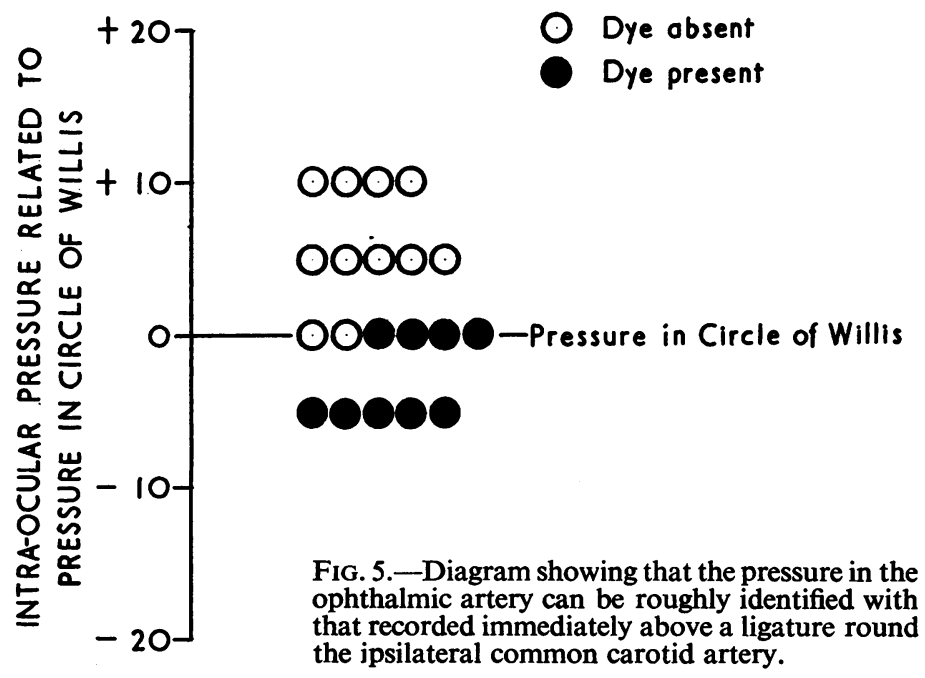


When the intra-ocular pressure was maintained at the same level as the reading from the distal cannula, an indeterminate result was obtained, but when the pressure was $5 \mathrm{~mm}$. Hg below the level of that in the circle of Willis, dye was constantly present in the eye.

Altogether the pressure on the circle of Willis and the aortic blood pressure were taken in 26 cases, although only twenty experiments are accepted as valid for the measurement of the pressure in the ophthalmic artery. The drop in pressure distal to the ligature ranged from 30 to 70 per cent. (average $49 \cdot 7$ per cent.).

\section{Notes on Particular Experiments}

In all, over a hundred rabbits were operated on, but many of these were consumed during the development of the method. In some of them special investigations were carried out, apart from the main theme of the experimental study.

(1) Experiments confirming the Findings of Sautter and Seitz (1952).Three rabbits were subjected to an identical procedure with identical results.

(a) The left eye was prepared as in the previous experiments, except that the needle from the pressure apparatus was not inserted. Instead the optic nerve was clamped with Spencer Wells forceps.

(b) $20 \mathrm{ml}$. of 10 per cent. Pontamine sky blue were injected intravenously.

(c) After allowing 5 minutes for the dye to become adequately mixed with the circulating blood, the eyes were removed.

Results showed that there was no blue dye in the retina of the experimental eye, but plenty in that of the control eye. These results suggest that clamping off the central retinal artery cuts off the only functional blood supply to the retina, and that no blood reaches it from the choroidal circulation.

(2) Experiment 38.-As carotid cannulation was sometimes impossible, a check was made to see whether femoral cannulation gave the same results with the method employed. This, in fact, was so: cannulae in the femoral and carotid arteries gave identical readings when each was connected alternately to the same manometer. The general condition of the animal was good throughout the experiment, and several readings were made.

\section{Discussion}

It is difficult to discuss the findings recorded above in relation to those of other workers in this field; different techniques and experimental animals make any true comparison impossible.

Similarly, any precise application of these results to human pathology would be highly dangerous, and is certainly not intended. 
The method has certain advantages that are naturally conferred upon it by the experimental animal. It has a most definite end-point; either dye reaches the eye or it does not. Even the smallest pulsation or seepage of blue blood will immediately result in the stain being taken up by the vessel wall, as well as by the erythrocytes and plasma, which are of course already stained.

Furthermore, the nature of the presentation of the results allows them to be preserved indefinitely, at any time available for inspection.

(1) Control Series.--In these experiments an attempt has been made to define the normal ophthalmic arterial pressure of the rabbit in relation to the normal systemic arterial pressure. Results indicate that it is within $5 \mathrm{~mm} . \mathrm{Hg}$ of the pressure in the aorta when this is measured by the method described.

Duke-Elder (1926) studied this problem in the cat with apparently similar results. However, the cat possesses a well developed carotid rete which gives rise to the ophthalmic arteries, and what proportion of the fall in pressure-if any-this absorbs, is unknown. This structure is of course not present in man, nor in the rabbit.

Furthermore, Duke-Elder's technique of estimating the blood pressure is slightly different from that used in the present series. In his results he talks of a mean aortic pressure, this being the mean value of the combined systolic and diastolic pressures.

The cannulation method described above gives almost no indication of the pulse pressure, as only a very slight movement can be seen in the mercury column. A pulsation can be seen in the cannula as it enters the common carotid artery, so presumably this is absorbed by the elasticity of the tubing and the weight of the contained saline and mercury.

However, although the manometer reading might bear an uncertain relation to the systolic peak in the aorta, this objection does not apply to the method used to determine the ophthalmic arterial pressure. Here even a tiny pulsation at a higher level than the intra-ocular pressure will leave its blue stain in the retinal vessels, so that the absence of dye on the resulting slide must indicate a definite relationship between peak systolic pressure in the ophthalmic artery and intra-ocular pressure.

Two alternative interpretations are available:

(a) If it is accepted that the method described above gives a blood pressure reading corresponding to the mean aortic pressure similar to that described by Duke-Elder, then the ophthalmic systolic peak is $5 \mathrm{~mm}$. $\mathrm{Hg}$ less than this. Assuming a pulse pressure of $30 \mathrm{~mm}$. $\mathrm{Hg}$, this would result in a drop of approximately 20 $\mathrm{mm}$. $\mathrm{Hg}$ from the systolic aortic pressure to the ophthalmic arterial peak.

Such a drop would not be in conformity with the results of other workers. Duke-Elder reported a drop of only $5 \mathrm{~mm}$. $\mathrm{Hg}$ from the aorta to the ophthalmic artery, and that in the cat in which, as mentioned above, there is a carotid rete.

Note should also be made of the work of Woodhall, Odom, Bloor, and Golden (1952) and Bakay and Sweet $(1952,1953)$ who found, from human experimental 
studies, a drop of only 1 per cent. in the systolic pressure from the main trunk of the internal carotid down to the branches of the anterior and middle cerebral arteries of only $0.5 \mathrm{~mm}$. in external diameter.

While acknowledging the dangers of comparing the results from other sources with the present experiments, as stressed already, it must be stated that similar studies in the rabbit are not available.

As the vascular arrangements in the rabbit approximate more closely to those in man than to those in the cat, a figure of $20 \mathrm{~mm}$. $\mathrm{Hg}$ for the fall in mean pressure from the aorta to the ophthalmic artery would seem open to question, for in both man and rabbit the vascular pathway from the aorta to the eye offers nothing like the opportunities for loss of pressure that are presented by a carotid rete.

(b) If, however, the method described above is accepted as giving a reading of the aortic blood pressure that approaches more closely to the systolic peak, any apparent discrepancy between this work and that of Duke-Elder is removed.

The ophthalmic arterial pressure is now represented as within $5 \mathrm{~mm}$. $\mathrm{Hg}$ of the aortic pressure.

It is interesting also to note the results of Hill and Flack (1912) and Hill (1913). Taking the blood pressure by a similar method to that used in this series, namely by a cannula in the carotid connected to a mercury manometer, they found that the intra-ocular pressure had to be raised almost to that of the carotid before bleeding ceased from a cut in a vortex vein. They too used rabbits. Their results, of course, prove nothing so far as the retinal circulation is concerned, the choroidal circulation in the rabbit coming from the external carotid artery.

It would seem odd, however, if there was a marked difference in the pressures of the retinal and choroidal circulations. So far as the cat is concerned Duke-Elder regards them as being equal.

Just how far, if at all, the results of these several workers are applicable and comparable to those reported above it is impossible to say. Until a more accurate and sensitive method of measuring the rabbit's blood pressure becomes available, all that can be done is to reiterate that the control series showed a systolic ophthalmic arterial pressure within $5 \mathrm{~mm}$. $\mathrm{Hg}$ of the recorded aortic blood pressure.

(2) Series 1.- In these experiments the intra-ocular pressure on the same side as the ligated carotid artery was varied in relation with the blood pressure. As the intra-ocular pressure was lowered, it became clear that there was a critical level at which some animals gave a positive and others a negative result.

The majority of the experiments were therefore concentrated round this pressure which was $50 \mathrm{~mm}$. $\mathrm{Hg}$ below the blood pressure.

The slides from experiments where the intra-ocular pressure was $50 \mathrm{~mm}$. $\mathrm{Hg}$ less than the blood pressure yield varied results. There is no dye in four of them, showing that in these cases the intra-ocular pressure was higher than 
that in the ophthalmic artery, and in another four there is clear evidence of the reverse being the case. In Experiments 59 and 63, however, although the control eye shows good penetration of dye, the experimental eye is only just stained, and that not completely, implying that the circulation must have been very meagre and that the intra-ocular pressure must have been very close indeed to that in the ophthalmic artery.

From this evidence it may be suggested that the systolic pressure in the ophthalmic artery is in the region of $50 \mathrm{~mm}$. $\mathrm{Hg}$ below the aortic blood pressure as recorded above, when the common carotid of that side has been ligated.

In all, the blood pressure was recorded accurately in 66 rabbits. This includes the animals used for all series of experiments ( 57 rabbits) with another nine in which the blood pressure readings were accurate, but in which the experiment was invalid for some reason. The blood pressure varied from 60 to $150 \mathrm{~mm}$. $\mathrm{Hg}$, but the majority of the readings were between 85 and 115 $\mathrm{mm}$. $\mathrm{Hg}$.

The average blood pressure in Series 1 was $108 \mathrm{~mm}$. $\mathrm{Hg}$ compared with $105 \mathrm{~mm}$. Hg for the total series. This slightly higher reading is probably due to the fact that in Series 1 the experiment involved very little disturbance to the rabbit-less than in the control series, where the rabbit had to be turned over after inserting the cannula, and much less than in Series II, where the extra manipulation resulted in a uniformly poorer general condition and a lower blood pressure.

A pressure of $50 \mathrm{~mm}$. $\mathrm{Hg}$ less than an average aortic pressure of $108 \mathrm{~mm}$. $\mathrm{Hg}$ would be $58 \mathrm{~mm} . \mathrm{Hg}$, or 54 per cent. of the systemic blood pressure. It may be reasoned that, after ligation of the common carotid artery, the ophthalmic arterial pressure on the affected side is in this region.

(3) Series 2.-By recording the pressure distal to the ligature round the common carotid as well as the blood pressure proximal to it, further information and experimental scope was gained.

In all, 26 rabbits had the pressure measured on both sides of the ligature. The average blood pressure was $98 \mathrm{~mm}$. $\mathrm{Hg}$ and the average pressure distal to the ligature was $49 \mathrm{~mm}$. $\mathrm{Hg}$ (50 per cent.).

This makes an interesting, though not necessarily true, comparison with the figure of 51 per cent. reported from similar measurements in man by Sweet and Bennett (1948) and Sweet, Sarnoff, and Bakay (1950).

The question whether the method of recording the blood pressure in use gives a reading of the mean or systolic pressures has already been discussed, but a further point may be added. The cannula recording the pressure in the circle of Willis showed that the blood stream in this part of the circulation had little or no pulse pressure. Even on withdrawing blood backwards into the tubing it seeped forwards gradually without pulsation. 
In view of this it may be assumed that the method in use would measure the ophthalmic artery pressure exactly, as there was only one pressure in most cases, with no systolic or diastolic excursion.

What proportion of the circle of Willis is subject to the fall in pressure after ligation of the carotid may be inferred from the experiments of MacDonald and Potter (1951), which clearly place the origin of the superior ophthalmic artery in the low pressure segment.

This segment is fed by the anterior and posterior communicating arteries. Any additional blood would probably come by retrograde flow back along the ophthalmic artery from its anastomosis with the external carotid. This anastomosis is probably not so rich as in man, because the superior ophthalmic artery is a relatively smaller vessel in the rabbit than the ophthalmic artery in man.

In the experiments performed in this series, the normal supply to this anastomosis in internal carotid occlusion is cut off, and any flow from the external carotid would have to be fed by its fellow on the other side via anastomoses in the midline.

The results obtained in this series seem quite clear. When an attempt was made to keep the intra-ocular pressure at the same level as that in the circle of Willis, an indeterminate result was obtained. When, however, the pressure was raised as little as $5 \mathrm{~mm}$. $\mathrm{Hg}$ above that in the circle, it prevented blood from reaching the eye in every case, and when it was $5 \mathrm{~mm}$. $\mathrm{Hg}$ below, then dye constantly reached the eye.

Thus there seem to be grounds for identifying the pressure in the ophthalmic artery with that taken distal to a ligature round the common carotid arterywithin $5 \mathrm{~mm}$. Hg either way.

It is interesting to compare the figure of 54 per cent. of the blood pressure which was postulated from Series I as an approximation to the ophthalmic arterial pressure after carotid ligation, with the more accurate measurement of 50 per cent. from the present series.

\section{Clinical Aspects of Carotid Occlusion}

Before attempting to assess the significance of these experiments, it is necessary to review certain aspects of the syndrome of carotid occlusion.

(1) Historical Survey.-It seems that Thomas Willis (1683) knew of carotid artery occlusion. In his "Two Discourses concerning the Soul of Brutes", he describes an autopsy where the internal carotid and vertebral arteries of one side were both calcified. The patient had not suffered from any "astonishing disease" before death.

Two centuries later the pathological entity described by Thomas Willis was becoming a more frequent diagnosis. Kussmaul (1872) and Penzoldt (1881) both recorded cases mainly diagnosed post mortem but occasionally 
suspected during life. They both recognized a form of "carotid hemiplegia" where optic atrophy on the side of the occluded carotid was associated with a crossed hemiplegia. Penzoldt also recorded the case of a patient who had complained of transient attacks of blindness which was diagnosed during life by the absence of pulsation in the cervical carotid of the corresponding side. This case was verified post mortem.

Following these Continental writers relatively little interest was shown in the English-speaking countries.

A case was reported by Cushing (1900), but he unfortunately did not state whether the affected vessel was the common or internal carotid.

Guthrie and Mayou (1908) also reported a patient with internal carotid thrombosis who had optic atrophy associated with a crossed hemiplegia, but it remained for Hunt (1914) to establish the syndrome of carotid hemiplegia and to issue a warning that the condition was more common than was generally realized.

This warning went almost unheeded: one case was reported by Hyland (1933), but it was only after an angiographic demonstration of carotid occlusion by Egas Moniz (1927) that the diagnosis came to be made frequently and while the patient was still alive.

Cases were reported by Riechert (1938), Chao, Kwan, Lyman, and Loucks (1938), Sorgo (1939), Galdston, Govons, Wortis, Steele, and Taylor (1941), and King and Langworthy (1941). Most of these had been diagnosed by angiography, although many were suspected on clinical grounds. Furthermore, it was rapidly being realized that the classical complex of optic atrophy and crossed hemiplegia was not always present.

It remained for Hultquist (1942) to show, from the results of 1,400 unselected autopsies, that thrombosis of a carotid artery, present in 3 per cent. had often been completely unsuspected during life. Indeed, in cases of internal carotid occlusion below the level of the ophthalmic artery, only a third showed cerebral damage.

Thence forward many other workers reported the condition. Amongst these were Erikson (1943) and Andrell (1943), who particularly stressed the visual symptoms. Krayenbühl and Weber (1944) reintroduced the technique of ophthalmodynamometry (Bailliart, 1917) as a diagnostic weapon but, although they reported encouraging results and all their cases were confirmed by angiography, their lead was not followed for some time. Further cases were reported by Wolfe (1948); Ameli and Ashby (1949); and de Jong (1949), and the subject was reviewed by Sugar, Webster, and Gurdjian (1950), who defined no less than four clinical types: fatal.

(a) An explosive type, leading to a major cerebrovascular accident, and often

(b) A slowly progressive type of more gradual onset, frequently presenting as transient attacks of hemiplegia that became permanent. 
(c) Thrombosis of the types recorded above, but with visual symptoms.

(d) A silent type, found quite unexpectedly.

Denny-Brown (1951) explained the transient symptoms sometimes seen by his theory of haemodynamic crises, and Shapiro (1952) gave details of the anastomotic pathways between the ophthalmic artery and the external carotid that might enlarge in carotid occlusion.

Other contributions came from Cloake (1951), who reviewed the subject, Elvidge and Werner (1951), Wagener (1952), Poppen and Baird (1952), who compared the effects of pathological occlusion of the artery with those of surgical ligation, Chambers (1954), Ochs, Sensenbach, and Madison (1954), and Shapiro and Peyton (1954) who gave a most concise and lucid review of the whole syndrome.

A notable contribution was that of Fisher $(1951,1952,1954)$, who has made an extensive study of the problem. He showed that, in addition to the four types of onset enumerated by Sugar and others, there were groups of patients presenting as cases of cerebral tumour or psychiatric disturbance who were also suffering from carotid occlusion. Fisher also reviewed some of the visual symptoms found in these cases, and this work will be considered in the next section.

The commonest site for the obstruction was in the internal carotid just distal to the carotid sinus, the carotid syphon being the next in order of frequency, although no part of the artery was exempt from atherosclerotic changes (Samuel, 1956). Indeed the local pathology was found to be atherosclerosis in the overwhelming majority of cases (Hultquist, 1942; Fisher, 1951, 1954; Cloake, 1951; Yates, 1954; Hutchinson and Yates, 1956, 1957; Samuel, 1956), and this has been confirmed by specimens removed at operation (Strully, Hurwitt, and Blankenberg, 1953; Eastcott, Pickering, and Rob, 1954; Denman, Ehni, and Duty, 1955; Edwards and Rob, 1956; Cooley, Al-Naaman, and Carton, 1956; and Lin, Javid, and Doyle, 1956).

It seemed remarkable that a lesion fairly constant in position should give rise to such a multiplicity of symptoms, and Hutchinson and Yates (1956, 1957) recalled, as had done Denny-Brown (1951), that atherosclerosis is a generalized disease, and that arteries other than the carotid might also be involved in the disease process. They therefore made a search for signs of sclerosis in the vertebral arteries.

So heavily involved were these vessels in patients previously thought of only as cases of carotid occlusion, that Hutchinson and Yates suggested that the two conditions should not be considered as separate entities but always together.

For this clinico-pathological combination they proposed the term "carotico-vertebral stenosis". It seems likely that the several modes of onset and clinical pictures described for carotid occlusion could be explained by various degrees of obstruction also existing in the vertebral arteries. 
(2) Visual Lesions in Carotid Occlusion.-It has long been known (Kussmaul, 1872; Penzoldt, 1881; Gowers, 1893; Siegrist, 1900) that occlusion of the carotid, whether surgical or pathological, may give rise to visual symptoms. Indeed, optic atrophy was an essential component of the syndrome of carotid hemiplegia (Hunt, 1914) and, although other ophthalmic symptoms (such as strabismus, ptosis, and pupillary abnormalities) were reported (Siegrist, 1900), it was only after the introduction of angiography in the diagnosis of the condition (Egas Moniz, 1927) that visual lesions other than optic atrophy came to notice in any quantity.

These were well summarized by Johnson and Walker (1951), who collected all the cases that had been reported up to that date. They concluded that the two commonest lesions were homonymous hemianopia and uniocular blindness, although diplopia, ptosis, papilloedema, and pupillary changes did occur. Of these, it is felt that only uniocular blindness can be related directly to pressure changes in the ophthalmic artery, and this alone will be discussed in detail. As has been mentioned already, homonymous hemianopia, the commonest visual lesion, has been ascribed with some certainty to lesions affecting the deep optic branches of the middle cerebral artery (Walsh and Smith, 1952).

Uniocular blindness may be transient or permanent; each will be considered separately.

(a) Transient Amaurosis.-Penzoldt (1881) was probably the first to associate attacks of transient amaurosis with carotid occlusion. Gowers (1893) made no mention of them, but Siegrist (1900) reported them following ligation of the carotid. Medical literature from this period shows, however, that attacks of transient blindness were well known, but were all considered to be cases of central retinal artery embolism (Mauthner, 1874; Loring, 1874; Nettleship, 1879; Priestley Smith, 1884; Coats, 1906; Werner, 1913; and more recently Minton, 1936).

Only after Egas Moniz (1927) introduced angiography in the diagnosis of carotid occlusion was the link between it and transient amaurosis appreciated, and that not rapidly. Andrell (1943) reported a case of transient amaurosis associated with attacks of transient hemiplegia which was proven angiographically, but Johnson and Walker (1951) found only five cases out of 107 with transient amaurosis as a premonitory symptom, and Wagener (1952) questioned the association of the two conditions, although Denny-Brown had no doubt.

It remained for Fisher (1952), in a comprehensive review, to collect 150 cases that could fall into the category of transient blindness, mostly uniocular, and to show the association between this and contralateral hemiplegia. He produced seven cases of his own to support this contention, but the diagnosis was only certainly confirmed in two of these, and was based on the absence of pulsation over the cervical carotid in another three. 
That Wagener's doubt was justified there can be no gainsaying. All the evidence produced showed that the association of the two conditions might be irregular to say the least. Attacks of transient amaurosis could come on quite unassociated with the hemiplegic symptoms. They could number several a day or a few in a year. Furthermore they often stopped completely when the hemiplegic symptoms became permanent, or more contrarily, transient attacks of blindness associated with hemiplegia progressed to permanent optic atrophy as the attacks of hemiplegia stopped.

These facts prompted Walsh and Smith (1952) to state that homolateral blindness, either permanent or temporary, could be the only symptoms of carotid occlusion, a fact that was demonstrated very clearly by Gordon (1959).

With the increasing recognition of transient amaurosis as part of the carotid occlusion complex, reports of its frequency have varied. At first barely 5 per cent. of cases were thought to suffer from it, but this figure is probably too low. Conversely, Gordon's impression may be too high, as much of his material came from Moorfields. The true figure is probably nearer 10 per cent.

Theories for the mechanism of this interesting, and for the patient extremely alarming, condition are several.

It has been suggested that multiple emboli are the cause. These temporarily occlude the mouth of the central retinal artery, and then sweep on down the ophthalmic artery. However, no damage to other parts of the ophthalmic circulation has been reported. This explanation was invoked (and later discarded) by Loring (1874) and others to account for the recovery of vision sometimes seen after what was then recognized as embolism of the central retinal artery. Gordon (1959) points out that the stereotyped nature of the episodes counts heavily against it.

Recently this theory has been given fresh impetus by Fisher (1959), supported by Denny-Brown (1960). These workers contend that recurrent emboli composed of fibrin are the cause of the amaurotic episodes. These emboli presumably arise at the site of the atheromatous plaque in the carotid, and Denny-Brown (1960) claims to have produced similar embolic plugs by damaging the middle cerebral artery of monkeys. The ultimate fate of the emboli is less certain; they seem to diminish in size and to be fragmented and dissolved in the circulation.

In spite of the initial attraction of this explanation, there are at least two major objections. First, Fisher has observed only one patient with this phenomenon, and similarity to Fisher's case is not a striking feature of the reports of other physicians who have observed attacks of transient amaurosis ophthalmoscopically. Fisher himself draws attention to this point. Secondly, the time relationship of Fisher's case does not fit in with that normally observed. The commonest type of amaurotic attack lasts for only a few minutes, sometimes for only 30 seconds and very frequently not more than 5 minutes. In Fisher's case there was a gradual restoration of vision over a period of 50 minutes. From this a further point may be raised. Fisher's 
patient recovered his vision sector by sector as the presumed fibrin plug was fragmented and swept towards the periphery. This is not the usual experience. Normally vision is suddenly totally lost, and often equally suddenly regained. At other times vision returns more slowly, as through a mist, but the whole visual field returns evenly. It is rare for patients to describe their vision as returning quadrant by quadrant.

The two remaining and most strongly favoured theories are vascular spasm, as postulated by Fisher (1952) and supported by Wagener (1952), Yates (1954), and Hutchinson and Yates (1957), and redistribution of the blood stream, as postulated by Denny-Brown (1951) in his theory of haemodynamic crises, supported in turn by Eastcott, Pickering, and Rob (1954), Wood and Toole (1957), and Symonds (1955).

The evidence of those who have actually observed a patient in one of these attacks casts doubt on the theory of spasm. Mauthner (1874), Werner (1913), and Hollenhorst (1959) reported how the retinal vessels immediately before and after an attack were of normal appearance, but became empty as soon as vision was lost. Mauthner called this "a sudden anaemia of the retinal arteries". Alternately the vessels became empty after the most delicate pressure on the globe. Hollenhorst describes such a case as this. He attempted dynamometry, but the retinal vessels became almost invisible as soon as he applied the instrument to the eye, yet as soon as vision returned so did the blood flow, and the vessels immediately resumed their normal appearance. There was no gradual relaxation of spasmic contraction, nor did the patient complain of any other symptoms. The whole phenomenon resembled a purely passive emptying and filling of the vessels. The normal appearance of the vessels between the attacks has also been confirmed by Walsh (1957), although he never actually saw his patient during an attack.

The theory of haemodynamic crises, however, gains some support from the fact that some, but not many, sufferers from transient amaurosis have pathological lesions elsewhere in the body that might cause diversions of the blood stream in times of crisis. Furthermore, attempts to reproduce haemodynamic crises clinically have not been convincing (Denny-Brown, 1960).

Neither of these last two theories has any direct experimental evidence to support it, and there is very little clinical evidence and that mostly negative.

Attacks resembling transient amaurosis have been produced experimentally by subjecting volunteers to the effects of centrifugal force. When the systolic blood pressure at head level was reduced to $20 \mathrm{~mm}$. $\mathrm{Hg}$ blindness occurred, vision returning when the pressure rose above this level (Behrman, 1951). The blindness was of course bilateral and, while the results are suggestive, it must be recalled that the whole of the visual pathway, not just the ophthalmic artery, was also subjected to this blood pressure with unknown effect.

As already stated, the information given by ophthalmodynamometry, although interesting, is not sufficiently accurate to be of great value in a problem such as this; indeed further information on the pressure changes in 
the ophthalmic circulation during carotid occlusion is badly needed, as many of the theories discussed above can muster but slender evidence in their support.

(b) Optic Atrophy.-The literature on the association of unilateral optic atrophy with crossed hemiplegia is indeed the history of carotid hemiplegia, which has already been briefly related above. There are, however, certain points requiring further discussion.

The term optic atrophy describes the end-result that covers a wide range of appearances seen immediately after the occlusion. Although the eye may be blind at this stage, its appearance may vary from complete normality to one of gross arteriosclerotic involvement, superimposed upon which may be the signs of central retinal artery occlusion in any degree of severity.

Whether the optic atrophy develops after attacks of transient amaurosis or not, it may be the only sign to indicate the diagnosis, and the condition may indeed be regarded purely as a central retinal artery occlusion. This point was mentioned by Walsh (1957), and has recently been dramatically demonstrated by Pickering (1958).

Two main theories have been advanced to explain the development of optic atrophy in carotid occlusion.

The original theory of carotid hemiplegia was that the thrombus extended up the carotid artery all the way to the ophthalmic artery and directly involved the central artery of the retina.

The alternative theory was that of embolism from the thrombus in the carotid to the central retinal artery.

That extension of the clot from the carotid to the eye does occur has been proven at post mortem many times (Kussmaul, 1872; Penzoldt, 1881; and many others). That it is not the only cause of the blindness seen in carotid hemiplegia is equally certain. However inaccurate the results of ophthalmodynamometry are thought to be, they certainly show that in the vast majority of cases blood is found to be pulsating through the central retinal artery far too soon for recanalization to have taken place in the thrombosed vessel. Some other explanation must be found for these cases.

As an alternative, embolism would seem more attractive, either from a mural thrombus, or as a piece detached from a propagated clot. This would explain those cases of blindness associated with incomplete carotid stenosis, but is not completely satisfactory. In cases of carotid obstruction with optic atrophy but no other abnormality, it may be argued that the central retinal artery is the only end artery among the branches of the ophthalmic, and therefore the only one to give rise to ischaemic symptoms on occlusion; there are however many branches that have but a poor anastomosis with their neighbours, for example the choroidal vessels (Wybar, 1954), and it may be doubted whether their collateral circulation would stand up to complete occlusion without some ischaemic manifestations. None has been reported. 
It seems hardly credible that the embolus should always pass down the central retinal artery and go nowhere else.

Reliable information on the pressure changes in the ophthalmic artery in carotid occlusion would be of considerable value in the reassessment of this problem.

(3) Diagnostic Methods.-Although clinical methods of establishing the diagnosis must remain pre-eminent, and indeed none would wish that it should be otherwise, two ancillary methods of diagnosis are of value in this condition, and each will be discussed in turn.

(a) Angiography.-When Egas Moniz (1927) introduced angiography in the diagnosis of cerebrovascular disease, a powerful new method was established of elucidating neurological problems. In his monograph (Egas Moniz, 1934), he enlarged and expanded his previous work, giving detailed accounts of technique, results, and complications, and mentioned that the ophthalmic artery was visible in about 50 per cent. of carotid angiograms, a figure that has been confirmed (Walsh and Smith, 1952). Egas Moniz, Lima, and de Lacerda (1937) were the first to report the diagnosis of internal carotid occlusion by angiography. This paper marked the beginning of a new epoch in the understanding of the condition, and the literature on radiological diagnosis must of necessity coincide with that of carotid occlusion from that date.

Apart from its immense diagnostic significance, angiography has also been of great value in investigating the pathways taken by the collateral circulation in carotid occlusion.

Anatomical studies by Fisher (1913), Lowrey (1916), Stopford (1916), Riggs and Griffiths (1938), Padget (1944), and Alpers, Berry, and Paddison (1959) have shown that irregularities in the circle of Willis are not uncommon, and the findings of these workers are fairly conformable. The artery most likely to be deficient is the posterior 'communicating, abnormality in the anterior communicating being much rarer. It seems clear also, from the evidence that Padget produced from a very large survey, that abnormalities of the circle of Willis are commoner in patients suffering from psychiatric disturbances or intracranial aneurysm. Sugar (1951) gave embryological explanations for these anomalies.

Cerebral angiography has shown from its inception that such anatomical irregularities are common. Under normal circumstances radio-opaque material injected into the common carotid would be seen only in the branches of that vessel. There would be no mixing in the circle of Willis with blood from other components. Torkildsen and Koppang (1951), however, showed that, in cases of carotid occlusion, angiography performed on the normal side could produce filling of the anterior and middle cerebral arteries of the occluded side-via the anterior communicating artery. 
This subject was taken up by Mount and Taveras (1957), who confirmed the findings of the anatomists, that the anterior communicating artery was a greater and more reliable source of collateral circulation than the posterior communicating.

A further source of collateral supply to the circle of Willis revealed by angiography is the reversed flow down the ophthalmic artery. The source of this blood is of course the external carotid artery via its rich anastomosis with the ophthalmic artery. This pathway was originally demonstrated by the experimental work of Elschnig (1893) and was also mentioned by Gowers (1893).

Angiographic proof that this is indeed a functional pathway was furnished by Marx (1949), Seaman, Page, and German (1949), Denny-Brown (1951), Sachs (1954), and Taveras, Mount, and Friedenberg (1954). Denny-Brown stated that he had never seen the anastomosis to be working less than 6 weeks from the time of occlusion. Of all the branches of the external carotid involved (François and Neetens, 1954; Mount and Taveras, 1957), the greatest flow is through the maxillary artery, and this is fed into the middle cerebral. Even when the anastomosis is well developed, the anterior cerebral receives its blood from the internal carotid of the other side via the anterior communicating artery.

(b) Ophthalmodynamometry.-This technique was popularized first by Bailliart (1917), and later by Magitot (1922). It was introduced as a means of measuring the pressure in the central retinal artery, but Duke-Elder exposed the fallacies of the method, pointing out that external pressure on the eye would cause a build-up of pressure in the central retinal artery until the pressure in the ophthalmic artery was reached, and that this, not the pressure in the central retinal artery, was what was measured by the technique.

Quite apart from this fundamental misconception, Duke-Elder (1926) also pointed out that such factors as intra-ocular pressure, scleral rigidity, and the direction of thrust of the ophthalmodynamometer piston, should all be taken into account.

Following these criticisms the technique was not employed to any degree in either the United Kingdom or the United States, although some Continental workers continued to use it.

With the more widespread recognition of the carotid occlusion complex which followed the introduction of angiography, ophthalmodynamometry again came to be considered as a diagnostic weapon. Many of the arguments levelled against it in the past no longer applied when it was used purely as a method of comparing the ophthalmic artery pressures of the two eyes of one patient. In most cases the two eyes are fairly alike in respect of such factors as size, shape, scleral rigidity, and intra-ocular pressure.

Indeed, reports of the value of the technique in the diagnosis of carotid occlusion soon appeared (Krayenbühl and Weber, 1944; Drew and 
Petrohelos, 1951, 1953; Thomas and Petrohelos, 1953), and Milletti (1950) showed that similar results could be obtained from external compression of the common carotid artery in the neck.

These findings have been confirmed (Svien and Hollenhorst, 1956; Heyman, Karp, and Bloor, 1957; Wood and Toole, 1957), and Spalter (1959) has added to the growing list of cases of carotid occlusion diagnosed by this method. An important contribution in Spalter's paper was his estimation of the accuracy of the procedure, and of the limits of experimental error to be expected in readings from the two eyes. He stated that a difference of more than 15 per cent. for the systolic, and 10 per cent. for the diastolic readings from the two eyes was to be considered significant.

Unfortunately, this is too large an error to allow anything but general inferences to be drawn from the results. The dynamometer gives results that suggest that the ophthalmic artery pressure is reduced to almost half its previous level in cases of carotid occlusion, but however suggestive these results may be, no firm conclusions can be drawn until a more accurate method of measuring the ophthalmic artery pressure is available.

\section{Possible Clinical Significance of These Experiments}

Earlier in this paper the dangers of drawing conclusions from animal experiments and applying them to man have been stressed. However, while such a process is dangerous, it is not necessarily impossible, provided that certain basic reservations are constantly borne in mind.

The theories accounting for the transient amaurosis and optic atrophy seen in carotid occlusion have been briefly analysed above. Apart from those well-established cases where the thrombus extended from the internal carotid to the central retinal artery, the explanations offered are somewhat specious, and as they have to account for all the cases of transient amaurosis and most of those of optic atrophy this is clearly a most unsatisfactory position. The theory propounded below is offered as an alternative.

The anatomy of the carotid arteries and the circle of Willis in the rabbit is not exactly the same as that in man, but is sufficiently close for it to be undeniable that pressure changes consequent on carotid ligation might be of a similar nature in both species.

Evidence has been produced above that in the rabbit the pressure in the ophthalmic artery is closely identified with that distal to a ligature round the ipsilateral common carotid artery, and from the anatomical evidence already given, it is again undeniable that a similar situation might exist in man.

To carry this hypothesis a stage further, let it be supposed that the variations in pressure distal to a block in the common carotid, as described by Sweet and his colleagues, could be accurately mirrored by a similar pressure in the ophthalmic artery. If this were so, then an average fall of 50 per cent. in pressure in the carotid would give a similar average drop in the ophthalmic artery. 
It must be emphasized that this figure of 50 per cent. is indeed an average finding; readings considerably less than this have been reported (Sweet and Bennett, 1948; Sweet, Sarnoff, and Bakay, 1950; Johnson, 1953; Woodhall, Odom, Bloor, and Golden, 1953), in some cases as low as 30 per cent.

Assuming a systolic blood pressure of $120 \mathrm{~mm}$. $\mathrm{Hg}$, this would give a pressure in the ophthalmic artery of only $36 \mathrm{~mm}$. $\mathrm{Hg}$ after occluding the common carotid.

The work of Duke-Elder may now be recalled again. His investigations on the cat showed that there was a drop of 25 per cent. in pressure from the ophthalmic to the central retinal artery.

For want of any other reliable figures on this problem, and purely as part of a hypothetical argument, these measurements from the cat will be applied to the present theory.

Thus a pressure of $36 \mathrm{~mm} . \mathrm{Hg}$ in the ophthalmic artery would give rise to a pressure of only $27 \mathrm{~mm}$. $\mathrm{Hg}$ in the central retinal artery.

This figure approaches the normal intra-ocular pressure.

It would seem then, that the transient amaurosis and optic atrophy associated with carotid occlusion could be explained on a simple pressure basis, without need to invoke the theories of embolism, haemodynamic crisis, or vasospasm.

It is suggested that these uniocular visual lesions occur because the pressure in the central retinal artery falls so low that it is either less than the intra-ocular pressure, or not great enough to satisfy the metabolic requirements of the retina.

Provided that this ischaemic period is short, the result will be transient amaurosis. If, however, it is so prolonged as to produce permanent damage to the retinal neurones, then the result will be optic atrophy.

It is admitted that this theory is based on a series of assumptions that may, or may not, subsequently prove to be false. Nevertheless, it is claimed that there is more evidence for it than for the theories of vasospasm, recurrent embolism, or haemodynamic crisis.

\section{Conclusions}

(1) The systemic blood pressure, estimated in 66 rabbits by the method described, averaged $108 \mathrm{~mm}$. $\mathrm{Hg}$.

(2) The systolic pressure in the superior ophthalmic artery is within $5 \mathrm{~mm}$. $\mathrm{Hg}$ of the systemic blood pressure.

(3) Ligation of the common carotid artery produces an average fall of 50 per cent. in the arterial pressure distal to the occlusion.

(4) The pressure in the superior ophthalmic artery of the ligated side is within $5 \mathrm{~mm}$. $\mathrm{Hg}$ of the pressure distal to the carotid occlusion. 
The experiments described in this paper were carried out in the Department of Pathology, Manchester University.

The author wishes to record his extreme debt to Professor A. C. P. Campbell, not only for allowing him the freedom of his department although employed elsewhere, but for his constant encouragement and advice.

Valuable technical assistance was given by Dr. A. Nicol of the Department of Pathology, and the illustrations were the painstaking work of the Department of Medical Illustration of Manchester Royal Infirmary, to both of whom the author gladly records his thanks.

\section{REFERENCES}

Alpers, B. J., Berry, R. G., and Paddison, R. M. (1959). A.M.A. Arch. Neurol. Psychiat., 81, 409 .

AMELI, N. O., and AshBy, D. W. (1949). Lancet, 2, 1078.

ANDRELL, P. O. (1943). Acta med. scand., 114, 336.

Bailliart, P. (1917). Ann. Oculist. (Paris), 154, 257.

BAKAY, L., and SWEET, W. H. (1952). Surg. Gynec. Obstet., 95, 67.

- (1953). J. Neurosurg., 10, 353.

Behrman, S. (1951). A.M.A. Arch. Ophthal., 45, 458.

Campbell, A. C. P. (1937). "The Circulation of the Brain and Spinal Cord", Res. Publ. Ass. nerv. ment. Dis., 18, 69.

Chambers, W. R. (1954). Surgery, 36, 980.

ChaO, W. H., Kwan, S. T., Lyman, R. S., and Loucks, H. H. (1938). Arch. Surg. (Chicago), 37, 100 .

Cloake, P. C. P. (1951). In "Modern Trends in Neurology", ed. A. Feiling, p. 480. Butterworth, London.

CoATs, G. (1906). Roy. Lond. ophthal. Hosp. Rep., 16, 262.

Cooley, D. A., Al-NaAman, Y. D., and Carton, C. A. (1956). J. Neurosurg., 13, 500.

Cushing, H. W. (1900). Bull. Johns Hopk. Hosp., 11, 260.

De Jong, R. (1949). Trans. Amer. neurol. Ass., 74, 52.

DenMAN, F. R., EHN, G., and DUTY, W. S. (1955). Surgery, 38, 569.

DenNY-Brown, D. (1951). Med. Clin. N. Amer., 35, 1457. (1960). A. M. A. Arch. Neurol., 2, 194.

Drew, A. L., and Petrohelos, M. A. (1951). Univ. Mich. med. Bull., 17, 282.

(1953). J. Neurosurg., 10, 74.

Duke-ELDER, S. (1926). Brit. J. Ophthal., 10, 513. (1958). "A System of Ophthalmology", vol. 1, p. 498. Kimpton, London.

EASTCOTT, H. H. G., PICKERING, G. W., and RoB, C. G. (1954). Lancet, 2, 994.

EDWARDS, C., and ROB, C. (1956). Brit. med. J., 2, 1265.

EGAS MONIZ (1927). Rev. neurol., 2, 72.

(1934). "L'angiographie cérébrale. Ses applications et résultats en anatomie, physiologie, et clinique". Masson, Paris.

LIMA, A., and LACERDA, R. DE (1937). Presse méd., 45, 977.

ELSCHNIG, A. (1893). v. Graefes Arch. Ophthal., 39, pt. 4, p. 151.

ELVIDGE, A. R., and WERNER, A. (1951). A.M.A.Arch. Neurol. Psychiat., 66, 752.

ERIKSON, S. (1943), Acta radiol. (Stockh.), 24, 392.

FisHER, A. G. T. (1913). J. Anat., 48, 37.

Fisher, C. Miller (1951). A. M. A. Arch. Neurol. Psychiat., 65, 346. (1952). A.M.A. Arch. Ophthal., 47, 167.

(1954). A.M.A. Arch. Neurol. Psychiat., 72, 187.

(1959). Neurology (Minneap.), 9, 333.

François, J., and NeETENS, A. (1954). Brit. J. Ophthal., 38, 472.

Galdston, M., Govons, S., Wortis, S. B., Steele, J. M., and TAYlor, H. K. (1941). Arch. intern. Med., 67, 1162.

GoRdon, N. (1959). Brit. J. Ophthal., 43, 257.

GOWERS, W. R. (1893). "A Manual of Diseases of the Nervous System", 2nd ed., vol. 2, p. 412. Churchill, London.

Guthrie, L. G., and MAYOU, S. (1908). Proc. roy. Soc. Med., 1, Sect. Clin., p. 180.

HENDERSON, E. E. (1903). Roy. Lond. ophthal. Hosp. Rep., 15, 260.

HEYMAN, A., KARP, H. R., and BLOOR, B. M. (1957). Neurology (Minneap.), 7, 97.

HILL, L. (1913). Proc. roy. Soc. Med., 6, Sect. Ophthal., p. 31.

, and FLACK, M. (1912). Proc. roy. Soc. B., 85, 439.

HOLLENHORST, R. W. (1959). Amer. J. Ophthal., $47,753$.

Hultquist, G. T. (1942). Quoted by Fisher, C. Miller (1951). 
Hunt, J. R. (1914). Amer. J. med. Sci., n.s. 147, 704.

Hutchinson, E. C., and Yates, P. O. (1956). Brain, 79, 319. (1957). Lancet, 1, 2.

Hyland, H. H. (1933). Arch. Neurol. Psychiat. (Chicago), 30, 342.

JoHnson, H. C. (1953). Surgery, 33, 537.

and Walker, A. E. (1951). J. Neurosurg., 8, 631.

KING, A. B., and LANGworthy, O. R. (1941). Arch. Neurol. Psychiat. (Chicago), 46, 835.

KrayenbüHL, H., and Weber, G. (1944). Helv. med. Acta, 11, 289.

Kussmaul, A. (1872). Dtsch. Klin., 24, 461.

LIN, P. M., JAVID H., and Doyle, E. J. (1956). J. Neurosurg., 13, 650.

LORING, E. G. (1874). Amer. J. med. Sci., 67, 313.

LOWREY, L. G. (1916). Anat. Rec., 10, 221.

MACDonald, D. A., and PotTeR, J. M. (1951). J. Physiol. (Lond.), 114, 356.

Magrtot, A. P. (1922). Amer. J. Ophthal., 5, 777.

MARX, F. (1949). Acta radiol. (Stockh.), 31, 155.

MAUTHNER, L. (1874). Amer. J. med. Sci., n.s. 68, 273.

Michaelson, I. C. (1954). "Retinal Circulation in Man and Animals", p. 29. Thomas, Springfield; Ill.

Milletti, M. (1950). Acta neurochir. (Wien), 1, 196.

Minton, J. (1936). Proc. roy. Soc. Med., 30, 285.

Moffat, D. B. (1952). Nature (Lond.), 169, 1015. (1956). Acta anat. (Basel), 26, 110. (1959). Personal communication.

Mount, L. A., and TaVeras, J. M. (1957). A.M.A. Arch. Neurol. Psychiat., 78, 235.

NeTTLESHIP, E. (1879). Brit. med. J., 1, 889.

OChs, L., SensenbaCh, W., and Madison, L. (1954). Amer. J. Med., 17, 374.

PADGET, D. H. (1944). In W. E. Dandy, "Intracranial Arterial Aneurysms", p. 67. Comstock, Cornell University, Ithaca.

Penzoldt, F. (1881). Dtsch. Arch. klin. Med., 28, 80.

PiCKerING, G. W. (1958). Trans. ophthal. Soc. U.K., 78, 295.

Poppen, J. L., and BAIRD, W. C. (1952). Surg. Clin. N. Amer., 32, 781.

RIECHERT, T. (1938). Nervenarzt, 11, 290.

Riggs, H. E., and Griffiths, J. O. (1938). Arch. Neurol. Psychiat. (Chicago), 39, 1353.

SACHS, E., Jr. (1954). J. Neurosurg., 11, 405.

SAMUEL, K. C. (1956). J. Path. Bact., 71, 391.

SAUTTER, H., and Sertz, R. (1952). v. Graefes Arch. Ophthal., $152,413$.

Seaman, W. B., Page, W. R., and German, W. J. (1949). Trans. Amer. neurol. Ass., 74, 55.

SHAPIRO, R. (1952). Radiology, 58, 94.

ShaPIRO, S. K., and PeYTon, W. T. (1954). Neurology (Minneap.), 4, 83.

SIEGRIST, A. (1900). v. Graefes Arch. Ophthal., 50, 511.

SMITH, PRIESTLEY (1884). Ophthal. Rev., 3, 1.

SorGo, W. (1939). Zbl. Neurochir., 4, 161.

SPAlter, H. F. (1959). Amer. J. Ophthal., 47, 453.

StOPFORD, J. S. B. (1916). J. Anat. Physiol. (Lond.), 50, 131, 255.

Strully, K. J., HurWitT, E. S., and BlankenberG, H. W. (1953). J. Neurosurg., 10, 474.

SugAR, O. (1951). Ibid., 8, 3.

Sugar, H. S., Webster, J. E., and Gurdjan, E. S. (1950). Arch. Ophthal. (Chicago), 44, 823.

Svien, H. J., and Hollenhorst, R. W. (1956). Proc. Mayo Clin., 31, 684.

SWEET, W. H., and BENNETT, H. S. (1948). J. Neurosurg., 5, 178. , SARNOFF, S. J., and BAKAY, L. (1950). Surg. Gynec. Obstet., 90, 327.

SYMONDS, C. (1955). Brit. med. J., 1, 119.

TAVeras, J. M., Mount, L. A., and Friedenberg, R. M. (1954). Radiology, 63, 525.

Thomas, M. H., and Petrohelos, M. A. (1953). Amer. J. Ophthal., 36, 335.

TORKILDSEN, A., and KOPPANG, K. (1951). J. Neurosurg., 8, 269.

WAGENER, H. P. (1952). Amer. J. med. Sci., 224, 229.

WALSH, F. B. (1957). "Clinical Neuro-ophthalmology", 2nd ed., p. 791. Williams and Wilkins. Baltimore.

W and SMIrH, G. W. (1952). J. Neurosurg., 9, 517.

WERNER, L. (1913). Trans. ophthal. Soc. U.K., 33,9.

WILLIS, T. (1683). "Two Discourses concerning the Soul of Brutes", p. 154. London.

WOLFE, H. R. I. (1948). Lancet, 2, 567.

Wood, F. A., and Toole, J. F. (1957). J. Amer. med. Ass., 165, 1264.

Woodhall, B., Odom, G. L., Bloor, B. M., and Golden, J. (1952). Ann. Surg., 135, 911.

$\overline{\text { WYBAR, K. C. (1954). }}, \overline{\text { Brit. J. Ophthal., 38, } 513 .}$

YATES, P. O. (1954). Proc. roy. Soc. Med., 47, 606. 